\title{
The Leadership Gap: Ensuring Effective Healthcare Leadership Requires Inclusion of Women at the Top
}

\author{
Kathryn J. McDonagh, Paula Bobrowski, Mary Ann Keogh Hoss*, Nancy M. Paris, \\ Margaret Schulte \\ ${ }^{1}$ Vice President Executive Relations, Hospira, Inc. 275 North Field Drive, Lake Forest, USA \\ ${ }^{2}$ College of Liberal Arts, 315-B Tichenor Hall, Auburn University, Auburn, USA \\ ${ }^{3}$ Eastern Washington University, 668 N. Riverpoint Blvd. Rm 338, Spokane, USA \\ ${ }^{4}$ Center for Oncology Research and Education, Atlanta, USA \\ ${ }^{5}$ Northwestern University, Masters of Science in Medical Informatics Program, Evanston, USA \\ Email: kathryn.mcdonagh@hospira.com, bobrope@auburn.edu, ․hhoss@ewu.edu, nparis@georgiacore.org, \\ nparis@georgiacore.org
}

Received 18 April 2014; revised 18 May 2014; accepted 25 May 2014

Copyright (C) 2014 by authors and Scientific Research Publishing Inc.

This work is licensed under the Creative Commons Attribution International License (CC BY).

http://creativecommons.org/licenses/by/4.0/

(c) () Open Access

\section{Abstract}

This paper argues that successful transformation of the healthcare system requires inclusion of women at the top. Women are missing in top leadership roles in healthcare at a time when the US healthcare system faces daunting challenges. There is a documented need for diverse leadership teams with transformational leadership skills to successfully lead organizations, yet women who comprise three fourths of the healthcare workforce are sparsely represented in board rooms and in the senior executive suite. Through a review the literature the authors explain why this leadership gap persists and recommend strategies to increase gender diversity in leadership ranks of the healthcare industry. Studies from other business sectors are also examined for application in healthcare. A lack of focus on female career development and succession planning, often based on persistent stereotypes about women leaders is a major deterrent to advancing women in top leadership positions. A compelling case is made for immediate remediation of this issue and implementing strategies to fill the leadership gap with talented women leaders. There is a demand to increase the number of women in top leadership positions in healthcare to assist in overcoming the current crises facing the industry.

\section{Keywords}

Healthcare, Leadership, Review, Stereotypes, Transformation, Women

\footnotetext{
*Corresponding author.
} 


\section{Introduction}

The tumultuous changes in healthcare today have raised concern about the availability and quality of strong leaders. Today's healthcare leaders must possess the characteristics required to lead systemic transformation toward a thriving and sustainable delivery system. Budget pressures, and demands for improved quality and access to care are driving fundamental change. The models of healthcare that were successful until recently emphasized disease and episodic care. These models are migrating toward a focus on wellness, prevention, primary care and increased patient autonomy and involvement in decision-making. This significant shift places more risk and accountability on the provider to develop innovative modalities of care with higher quality and at lower costs. This requires a more integrated model of care which in turn mandates a more collaborative and transformational leadership style, one that is often closely associated with women leaders (Barsh, Cranston, \& Lewis, 2009; Eagly \& Carli, 2007; Porter-O'Grady, 2003). A multitude of studies in the literature support the fact that diverse executive teams result in enhanced organizational performance, yet career development and succession planning for female leaders is not a priority for healthcare leadership (Blumenstein, 2011; Coffman, Gadiesh, \& Miller, 2010; McKinsey, 2010a). Women often possess the collaborative and transformational style of leadership required to manage in today's challenging times yet they often feel thwarted in their attempts to reach higher executive level positions. The percentage of female hospital chief executive officers (CEOs) has not changed significantly in decades (Lantz, 2008). Some of this persistent dilemma is related to stereotypes about women as leaders, women's experience in advancing their own careers, and organizational cultures and models that prevent the advancement of women to the top levels in healthcare (American College of Healthcare Executives, 2006; Eagly \& Karau, 1991; Flynn, Heath, \& Davis, 2011; McEldowney, Bobrowksi, \& Gramberg, 2009).

A crucial leadership gap exists in today's healthcare system. Women are missing in top leadership roles in healthcare, yet they are well suited for these leadership positions. Women make up the majority of students in medical schools and in graduate health administration programs (Aud, Hussar, Kena, Bianco, Frohlich, Kemp, \& Tahan, 2011; Lantz, 2008; Matus, 2003). The research literature regarding the gender gap in healthcare provides a framework to gain a better understanding of that gap, and thus help to define the research questions that are addressed. These questions revolve around the reasons for the persistence of the leadership gap in healthcare and the leadership challenges that this sector faces. Following this, the business case and strategies for increasing women in the top leadership ranks of healthcare are defined.

\section{Research Questions}

The research questions addressed in the current study include: Why is the gender gap in healthcare leadership persisting? In what way is gender diversity in healthcare leadership important? In addressing these questions, studies that validate the persistence of a gender gap are referenced, followed by a discussion of the reasons for the gap, and finally the importance of gender diversity and recommendations for change will be explored.

Many articles advocating for more diverse leadership teams in healthcare use a broad definition of diversity to address the many similarities and differences that make each individual unique (Dreachslin, 2007). With a specific focus on gender diversity, a precise definition is useful in addressing the issues related to diverse workforces, patients and cultural competencies. A precise definition brings focus to gender diversity and provides an opportunity to examine the unique issues related to gender diversity and healthcare leadership. Research by Dreachslin (2007) found that gender worked with race and ethnicity to exacerbate disparities in career attainment and satisfaction. Consequently, there is rationale for distinguishing these different factors for analysis. Myers and Dreachslin (2007) noted that the challenge for healthcare leaders is to understand that the majority and minority group members view equity and opportunity in the workplace very differently; while this is true for both gender and race/ethnicity groups, it is noteworthy that women actually comprise the majority of the healthcare workforce (US Bureau of Labor Statistics, 2010; World Health Organization, 2008).

There are tangible deficiencies in the leadership pipeline for racial and ethnic candidates to healthcare leadership positions. However, this is not the case regarding gender. There is an available pool of female leadership candidates. The question is: why are these women not advancing to executive and governing board leadership roles?

\section{Persistence of the Gender Gap}

In a study conducted on leadership cultivation in the healthcare industry in 2001, surveying CEOs of US hospit- 
als and health systems, concluded that many CEOs believe the healthcare industry drives away future leaders for a number of reasons:

(1) CEO's work unreasonably long hours. (2) Potential leaders are unwilling to spend hours working at the expense of their personal priorities. (3) A lack of financial resources does not allow for effective mentoring of future leaders. (4) Boards (of Directors) fail to commit to leadership development and succession planning. (5) Leaders (CEOs) fail to identify and develop successors. Sixty-seven percent of the CEOs who responded to the survey reported they were not investing in leadership career paths for potential future leaders but tended to create short-term management roles instead.

The majority of the CEOs also reported that they did not engage in future leader screening or evaluation (57 percent) and missed or ignored mentoring opportunities (75 percent). Approximately three out of four CEOs indicated that they prioritized strategic, financial, and operational issues over mentoring. The CEOs also believed they did a better job of mentoring future female executives than minorities into leadership roles because they perceived the talent pool of women to be larger (Witt/Kieffer, 2002 in Lantz, 2008).

According to a survey conducted by the American College of Healthcare Executives (ACHE, 2006), women in management positions are more likely than men to work in the position of department head or other staff member. Conversely, more men fill roles such as CEO, president, or vice president. Over a 15-year period that ACHE surveys were conducted, the proportion of female CEOs did not improve substantially.

ACHE has conducted a series of research surveys on gender and careers in healthcare management in 1990, 1995 and 2000. In December of 2006, the results of the 2006 survey were published in a report titled, "A Comparison of the Career Attainments of Men and Women Healthcare Executives." The major findings of this survey provide interesting information regarding women in healthcare management. For example, the survey found that more women than men are in management roles in specialized areas such as nursing, planning, quality assurance and the continuum of care. In contrast, a higher proportion of men than of women were found in general management. Earnings of men and women with equal levels of experience and education differed by almost $\$ 25,000$, just as it had in studies in 1990, 1995, 2000 (\$107,800 for women and $\$ 131,000$ for men) (ACHE, 2006).

A University of Michigan study conducted by Dunham and Yhouse (2007), examined the gender of chief hospital administrators in the United States. The assumption used for selection of these Solucient 100 Top hospitals was that leading, progressive hospitals are more likely to have significantly more women in top leadership positions. The results revealed that of the 474 chief administrators of the top hospitals, 114 (24 percent) were women. The researchers also found that 30 percent of the Solucient 100 Top Hospitals employed no female chief administrators, and 34 percent employed only one female chief administrator. These top hospitals have a higher percentage of females in leadership positions than the norm (Dunham \& Yhouse, 2007). The study highlighted that there has been little progress to close the gender gap in healthcare leadership, which is surprising against the backdrop of anticipated demand in hospital leadership in the near to mid-term outlook. The nation's top hospitals should be the leaders in an effort to remove gender bias in the selection of chief administrators (Dunham \& Yhouse, 2007).

Most of this information is known to women who are managers and administrators working in healthcare. What is most concerning is that while women support upward mobility of women, fewer of them are willing to try to attain leadership positions. Have the results of years of women not attaining these positions sent a message to the next generation that efforts are not rewarded? In fact, a national executive task force on women in the economy noted in their studies that women's desire to move to the next higher leadership level diminished as they aged due to the experience of thwarted ambition (Warner, 2011). Women lose interest more quickly than men in climbing to the next level professionally. But it is not for lack of ambition-the problem is largely a perceived lack of opportunity. Tapping women's enthusiasm before it is quashed-particularly at the middle management level where they feel more empowered and hopeful than women in entry-level jobs—could go a long way toward unleashing their potential (Blumenstein, 2011: p. R3).

\section{Challenges and Issues}

\subsection{Lack of Succession Planning}

To identify leadership challenges today, ACHE has tracked the hospital CEO turnover rate since 1981. In 1981, the first study showed a 14 percent hospital CEO turnover rate in the 5687 hospitals surveyed and in 2010 the 
CEO turnover rate increased to 16 percent. The national CEO turnover rate has fluctuated between 13 and 18 percent over the past 29 years, reaching its peak in 2009 (ACHE, 2011). Dolan (2011) states that median CEO tenure is four years, and 58 percent of the current CEOs are in their positions for less than five years. This degree of leadership change and instability suggests a need for effective succession planning. According to Dolan (2011) "Now, more than ever, hospitals need to ensure they have the appropriate succession plans in place to minimize any potential negative impact of unexpected turnover. It is crucial that hospital boards and CEOs work together to this end" (p. 1).

Lantz (2008) emphasized that despite widespread awareness of lack of women in the top echelons of healthcare leadership, actions are lacking such as succession plans that focus on a concrete plan for development of women for these positions. Bickel (2007), in discussing gender disparities and career development for women physiatrists, brings up the significant issues of salary and advancement. While there are more women in the pipeline, "increases in the number of women are not reducing gender disparities in advancement,” (p. 683). Bickel (2007) also addresses an issue found in both the administrative and clinical sectors of healthcare: more women are in practice and on executive management teams in mid-level roles. Since women are visible and represented in these areas, it is felt by many men that there is not a problem for women advancing in their careers. While women achieve these levels they do not advance to the top echelons within healthcare organizations. Yet, they represent a robust source of potential for advancement into those top echelons.

\subsection{Need for Transformational Leadership}

Leadership development programs are evolving in US health systems based on a comprehensive survey that demonstrated $52 \%$ of systems had such programs and an additional 12\% were developing programs (McAlearney, 2008). Two important reasons survey respondents cited for establishing leadership development programs were to advance the system's strategy and to initiate succession planning. However, there was no mention of a focus on gender diversity. This may confirm the apparent lack of priority on advancement for women in healthcare leadership. There may be a missed opportunity in not specifically engaging women in leadership development and maximizing their talent.

The capacity of healthcare to respond to escalating demands for transformation will be determined, in large measure, by its ability to create and sustain exceptional leadership teams. Traditionally healthcare has viewed the development of the skills and competencies of individual leaders as a proxy for creation of effective teams. According to the National Center for Healthcare Leadership (NCHL) however, leader development which focuses on building individual skills is not synonymous with leadership development. The latter is distinguished by enhancing the capacity of a team of leaders. Effective, influential leaders are those that catalyze teams to perform and serve at higher levels in order to produce theorganizational breakthroughs required in today’s healthcare environment (Garman \& Lemak, 2011).

One of the dominant themes in Collins (2001) research is that such breakthroughs are not the result of managing change, motivating people or creating alignment. Rather, the revolutionary process of transformation flows from the evolution of a capable individual (e.g. leader) into a contributing team member, a competent manager, and an effective organizational leader. The focus on vision, strategy, structure, and tactics will not transform the industry; only leadership will. Recognizing and defining the relationships between and among leadership and organizational performance is the key ingredient to the creation of high-performing systems and cultures of the future.

\subsection{Women as Transformational Leaders}

Effective leadership is generally considered to be an artful blend of intelligence, personality traits and management style. A comparison by Eagly and Carli (2007) indicates an overall gender balance in leadership aptitude and leads to their conclusion that "men and women differ little in the abilities that are most relevant to leadership,” (p. 42). Their research shows that general intelligence, which is generally equal in women and men, is a prerequisite for becoming a leader and that intelligence enhances both job performance and career attainment. In isolation, however, intelligence is an inadequate predictor of leadership effectiveness. Personality traits such as openness, extraversion, conscientiousness and agreeableness are also positively correlated with leadership. Of these, extraversion is the most consistently associated with the emergence and success of leaders and is relatively equal between women and men. In general, according to Eagly and Carli (2007), “sociable, assertive individ- 
uals who are open to new ideas and who are conscientious, honest, and trustworthy tend to become effective leaders," (p. 185).

Evidence points to gender balance with regard to intelligence and personality traits; however, male and female leaders do exhibit differences in management styles. The interactive style of women leaders described by Rosener (1990) facilitates inclusion while sharing power and information. Barsh et al. (2009) propose a constellation of capabilities based on their research which is called "centered leadership" and is associated with women who achieve high levels of performance. The five dimensions of centered leadership-meaning, engaging, connecting, managing energy and positive framing - promote both professional achievement and more desirable work-life balance as reported by McKinsey (2010b).

Women are also more inclined toward a style of transformational leadership. Transformational and transactional leadership theory was brought to prominence by Burns (1978). While transformational leadership is imbued with values and transcendence of short term goals in favor of higher order needs, transactional leadership relies on systems of "give and take" that appeal to the personal motivations of followers.

Transformational leaders are those who gain trust, confidence and build shared vision by serving as role models. They provide inspirational motivation, intellectual stimulation and rely on individualized consideration. Transformational leadership attributes are more closely aligned with female characteristics such as an interpersonally-oriented, participatory style.

\section{The Business Case for Gender Diversity in Leadership}

Demonstrating a strong business case or evidence of improved organizational performance related to gender diverse leadership is critical. Some of the rationale for promoting women to the top include better financial results, improved decision making, increased market share as well as a strategic advantage in hiring a well-educated workforce in an era of talent competition (Barsh et al., 2008).

Adler (2001) conducted a longitudinal 19-year study of 215 Fortune 500 firms which showed that firms with a high number of women executives outperformed their industry median firms on the three profitability measures used in the study. These measures were profit as a percent of revenue, profit as a percentage of assets and stockholders' equity. Additionally, the firms with the highest scores for promoting women were consistently more profitable than those whose scores were merely very good. This type of study cannot prove causality but it is clear from the multiple measures used in the study that there is a positive correlation between the presence of larger numbers of women in executive positions in a company and higher than normal profitability within the company's industry.

A Catalyst (2004) study analyzed a sample of 353 Fortune 500 companies for gender diversity and financial performance. The companies with the highest representation of women on their top management teams experienced better financial performance than the group of companies with the lowest women's representation. The finding held for two financial measures used; return on equity (ROE) which was $35.15 \%$ higher and total return to shareholder (TRS) which was $34 \%$ higher. These findings were true for all five industries studied and Catalyst Award-winning companies, which are role models for gender diversity, outperformed all others in the sample. Catalyst concluded that ultimately, the business case for recruiting, developing, and advancing women is to enable companies can make better decisions, produce better products, and retain key business advantages over more homogenous companies.

McKinsey \& Company has done extensive research on the relationship between organizational and financial performance and the number of women leaders (Barsh \& Yee, 2012; Desvaux, Devillard-Hoellinger, \& Meaney, 2008; McKinsey, 2010a; McKinsey, 2010c; McKinsey, 2012). Their global research with 115,000 firms has shown that companies with the highest scores on nine important dimensions of organization such as leadership, accountability and direction, are likely to have higher operating margins than their lower ranked counterparts. Second, the companies that had three or more women on their senior management teams scored higher on all nine organizational criteria than did companies with no senior-level women (Desvaux, Devillard-Hoellinger, \& Meaney, 2008; McKinsey's Global Survey (2010a). Another McKinsey study showed that companies with the highest share of women in executive management outperform companies with no women. The top quartile group exceeds return on equity by 41 percent over groups with no women. And for operating results, the more gender diverse companies exceeded by 56 percent the group of companies with no women (McKinsey, 2010c). In their research studies, McKinsey has found that companies have identified a compelling business case for gender di- 
versity including the ability to hire and retain the best talent, the ability to sustain client relationships and the ability to better understand insights from female consumers.

Another recent study of 60 companies demonstrated that women are entering corporations in large numbers but the pipeline still has blockages and barriers. This is demonstrated in the number of women who opt to take staff roles, get stuck in middle management or leave the organization (Barsh \& Yee, 2012). The pipeline of women is important to healthcare since the availability of women qualified for leadership roles in healthcare is a unique strength of the industry. However, the field's efforts at transformation may be encumbered by the lack of optimal inclusion of women on executive teams.

Reimbursement structures in healthcare are increasingly relying on quality improvement metrics. This means that, in order to achieve the financial performance results measurable quality improvement results are imperative. Zenger and Folkman (2012) studied gender differences in leadership based on 16 competencies of outstanding leaders. They report that "at all levels, women are rated higher in fully 12 of the 16 competencies that go into outstanding leadership. And two of the traits where women outscored men to the highest degree-taking initiative and driving for results-have long been thought of as particularly male strengths". In an environment that demand results as intensely as healthcare, the business case for women in top leadership is particularly compelling.

It is vital to build awareness of the business case for gender diversity within healthcare organizations since the compelling evidence so far has not resulted in significant change. Healthcare is facing transformational change which is being driven by the need to reduce costs and improve quality. Successful healthcare organizations will require improved financial performance which is one of the hallmarks of increased numbers of women in top leadership.

\section{Strategies for Increasing Gender Diversity in Leadership}

There is a plethora of recommendations to support increased gender diversity among healthcare executive leaders and board members. The authors recommend selected strategies that create the most leverage and drive success based on the review of the literature and their work with experts in the field.

\subsection{CEO and Board Accountability}

It is imperative that CEOs and governing boards commit to changes in the way top executives are chosen; indeed they are the only ones who can affect this change. A summit of almost 200 top leaders in government, business and academia addressing why women in America's workplace are falling back instead of making gains in leadership recommended creating accountability at the CEO and board levels to promote women at the top (Blumenstein, 2011). A CEO commission was recommended from leading companies to identify, drive and publish results to increase numbers of women at the top. Targets to advance women in senior management positions along with metrics and score cards would be published to promote accountability.

It is essential to provide opportunities for women not only in the top executive suite but in the boardroom as well since governing boards represent the highest level of organizational leadership and play an important role in executive placement. It is well documented that women make up only 15 percent of Fortune 500 board director positions and this has changed very little in over a decade (Catalyst, 2010). In healthcare, women make up a slightly larger proportion of board members at 28 percent in 2011 which is up from 23 percent in 2005 (Hassmiller \& Combes, 2012). Governing boards can benefit from fresh perspectives and diversity in thought. Additionally, women can bring a sense of urgency to addressing the lack of women in critical leadership roles.

\subsection{Succession Planning and Leadership Development}

High CEO turnover rates and lack of succession planning result in disruption to healthcare organizations and an inability to create and sustain change. When CEO positions are vacant, critical strategic initiatives such as physician recruitment and new service developments are often put on hold. In addition, the departure of a CEO often results in other senior leadership changes so continuity of strategies and transformational change is difficult at best. In addition to this volatility in hospital CEO positions there is a dearth of succession planning in healthcare compared to other industries. In a study of freestanding hospitals, only 21 percent conducted succession planning versus 57 percent in US public companies (Dolan, 2011). The National Center for Healthcare Leader- 
ship (2010) conducted a similar survey and found a lack of attention being paid to succession planning or talent management despite the fact that the need is even more pronounced in the dynamic and complex healthcare industry.

The National Center for Healthcare Leadership (2010) white paper on best practices in healthcare leadership talent management and succession planning provides case studies of best practices at North Shore-LIJ Health System, Virtua, and Moses Cone Health System. Exemplars such as these healthcare organizations and other business models, such as General Electric's renowned leadership development program, can be used to establish much needed programs in healthcare which are often underfunded or nonexistent.

This crisis in leadership demands creative solutions and a commitment to succession planning that the healthcare field has avoided to this point. Many female leaders are well equipped to assume greater leadership roles but are not being recognized as transformational leaders that can have a truly positive impact on healthcare.

\subsection{Objective Performance Evaluation Process}

Another critical area that organizations need to address is the performance evaluation process which often undermines opportunities for women to advance. Valian's (1998) work on gender schemas and how they disadvantage women professionally provides illumination into why the advancement of women has been so slow in coming. Valian contends that a set of implicit or non-conscious hypotheses about sex differences plays a central role in shaping men's and women's professional lives. The most important consequence is that men are consistently overrated while women are underrated. These small advantages and disadvantages accumulate and result in large disparities over time in salary, promotion and prestige. Although many women and men express egalitarian beliefs, they are often not aware of how these unconscious gender schemas are a factor in performance evaluations.

Education about these underlying biases is important to provide in organizations for leaders who will be conducting performance appraisals. Raising awareness of how gender schemas subconsciously influence what we pay attention to and interpretations of information should be a part of the human resource training for evaluations. Gender schemas for women are not compatible with professional management roles, which are traditionally viewed as part of the male schema (Valian, 1998). Those deeply embedded schemas have us expect less of women in management because women are primarily nurturing, communal and expressive so we tend to judge their professional performance as worse than it actually is. These evaluations aggregate to real accumulate disadvantages over time.

Evaluators should be enlightened about the effects of gender schemas and the importance of each evaluation in terms of the accumulation of advantage or disadvantage. Evaluation forms should be reviewed as well to ensure that unintended bias is not built into the process. Objective third party reviews of evaluations should also be done to detect bias. Valian (1998) suggests questions to ask should include, "How would I evaluate this performance if the person were a man rather than a woman?" or "How did I evaluate a man who performed this way?" (p. 309). Accountability for objective performance appraisals is crucial for developing a more balanced and equitable system.

\subsection{Corporate Culture Initiatives}

Corporations are beginning to realize that women constitute a large part of their talent pools in this era of leadership shortages and are developing programs to cultivate high potential executives. The global search for talent in the future will make it difficult to ignore women as the valuable resources they are in times of transformation. Some of the corporate initiatives that are most often utilized include flexible work schedules, leadership development programs, mentoring programs, networking events and corporate women networks. No one program is a panacea and various initiatives need to be adapted to meet the specific needs of that workplace population. It is the collective compendium of programs and commitment from executive leadership that promotes a cultural change that supports gender diversity in top roles.

A prominent example of this cultural transformation is the work Deloitte led in order to address the lack of female partners and the excessive turnover of women leaders. This movement from a corporate ladder milieu to a corporate lattice concept was a part of the cultural transformation that supported the advancement of women like never before (Benko \& Anderson, 2010). The lattice concept incorporates a new model of work that incorporates both the professional and personal goals of the individual and supports multidimensional career paths, 
high workforce mobility, and continuing career opportunities. This corporate flexibility and change in attitudes from the past is advantageous for both genders. In particular, it reduces the penalization of women when they temporarily digress from a career focus to balance family and work-life needs (it also benefits men who choose this path). Those types of diversions and the opportunity to experience new work skills no longer prevents the individual from attaining higher levels of responsibility in the future (Hoss, Bobrowski, McDonagh, \& Paris, 2011). Deloitte experienced many benefits from the corporate lattice program including retention of high-performing female talent, increased teamwork and collaboration, greater diversity of leadership and improved organizational performance.

\subsection{Individual Initiatives}

In addition to corporate programs that focus on advancement opportunities for females, women themselves have to take responsibility for overcoming the barriers to career advancement. A focus on networking is beneficial to overcome the isolation women often feel in the male dominated executive suite. Women often act as mentors and role models for other women. This is vital in career development. The use of male and female mentors and sponsors is a positive way to support leadership skill development and identify opportunities for advancement. Obtaining endorsement from a legitimate authority can increase chances of advancement, and for the person to actively seek out information about promotion possibilities, job openings and other advancement opportunities (Valian, 1998).

Barsh and Yee (2012) identified common attributes of the successful women leaders that they studied. These leaders had a robust work ethic, were results-oriented, had resilience, were persistent in getting feedback and were team leaders. They inspired and motivated teams to high levels of performance.

\section{Conclusion}

Women make up the vast majority of the healthcare workforce but have not attained a proportional level of top executive positions. This imbalance is driven by multiple causes including long held cultural attitudes about women in leadership and a lack of emphasis on corporate strategies to support the advancement of women to the top.

Some of the strategies recommended to address this issue include development of a corporate priority for gender diversity in executive leadership with CEO and board accountability; effective succession planning; implementation of leadership development programs that focus on gender diversity; adoption of objective performance evaluation process; and creation of corporate initiatives such as flexible work schedules, mentor programs, networking events, and corporate women networks.

Future research recommendations include analyzing the results from companies that have implemented leadership development programs with a focus on women, studying the percentage of women in executive roles in organizations that have robust succession plans and assessing the organizational performance results of gender diverse executive teams.

As healthcare organizations face an increasing demand for talent, it will be more difficult to ignore one half of the workforce that is capable of assuming top leadership roles. Healthcare is in turmoil now with tumultuous changes, disruption, and a need for transformational leadership. The irony is that many women are available and qualified to assume top executive positions. This leadership gap is clear and now is the time to tap into the transformational leadership attributes of women to lead healthcare into the future.

\section{References}

Adler, R. D. (2001). Women in the Executive Suite Correlate to High Profits. European Project on Equal Pay. http://www.w2t.se/se/filer/adler_web.pdf

American College of Healthcare Executives (ACHE) (2006). A Comparison of the Career Attainments of Men and Women Healthcare Executives. http://www.ache.org/pubs/research/gender_study_full_report.pdf

American College of Healthcare Executives (ACHE) (2011). Hospital CEO Turnover. http://www.ache.org/Pubs/Releases/2011/turnover.cfm.

Aud, S., Hussar, W., Kena, G., Bianco, K., Frohlich, L., Kemp, J., \& Tahan, K. (2011). The Condition of Education 2011. (NCES 2011-033). US Department of Education, National Center for Education Statistics. Washington DC: US Government Printing Office. 
Barsh, J., \& Yee, L. (2012). Unlocking the Full Potential of Women at Work. http://www.mckinsey.com/client_service/organization/latest_thinking/women_at_work.

Barsh, J., Cranston, S., \& Lewis, G. (2009). How Remarkable Women Lead: The Breakthrough Model for Work and Life. New York: Crown Business, Random House.

Benko, C., \& Anderson, M. (2010). The Corporate Lattice: Achieving High Performance in the Changing World of Work. Boston, MA: Harvard Business Review Press.

Bickel, J. (2007). The Work That Remains at the Intersection of Gender and Career Development. Archives in Physical Medicine and Rehabilitation, 88, 683-686. http://dx.doi.org/10.1016/j.apmr.2007.02.038

Blumenstein, R. (2011). A Blueprint for Change. The Wall Street Journal, R3.

Burns, J. M. (1978). Leadership. New York: Harper \& Row.

Catalyst (2004). The Bottom Line: Connecting Corporate Performance and Gender Diversity. http://www.catalyst.org/file/44/the\%20bottom\%20line\%20connecting\%20corporate\%20performance\%20and\%20gender\% 20diversity.pdf

Catalyst (2010). Catalyst Census: Fortune 500 Women Board Directors. http://catalyst.org/publication/460/2010-catalyst-census-fortune-500-women-board-directors

Coffman, J., Gadiesh, O., \& Miller, W. (2010). The Great Disappearing Act: Gender Parity up the Corporate Ladder. Bain and Company.

http://www.bain.com/publications/articles/the-great-disappearing-act-gender-parity-up-the-corporate-ladder.aspx

Collins, J. C. (2001). Good to Great. New York: Harper Collins.

Desvaux, G., Devillard-Hoellinger, S., \& Meaney, M. C. (2008). A Business Case for Women. McKinsey Quarterly. http://www.rctaylor.com/Images/A_Business_Case_for_Women.pdf

Dolan, T. (2011). The CEO Turnover and Succession Crisis. Healthcare Executive, 26, 6-8.

Dreachslin, J. L. (2007). Diversity Management and Cultural Competence: Research, Practice, and the Business Case. Journal of Healthcare Management, 52, 79-86.

Dunham, N., \& Yhouse I. (2007). Census of Women Chief Administrators of the Solucient 100 Top Hospitals. Unpublished Manuscript, Ann Arbor, MI: University of Michigan.

Eagly, A. H., \& Carli, L. L. (2007). Through the Labyrinth: The Truth about How Women Become Leaders. Boston, MA: Harvard Business School Press.

Eagly, A. H., \& Karau, S. J. (1991). Gender and Emergence of Leaders: A Meta-Analysis. Journal of Personality and Social Psychology, 60, 685-710. http://dx.doi.org/10.1037/0022-3514.60.5.685

Flynn, J., Heath, K., \& Davis, J. (2011). Break Your Own Rules: How to Change the Patterns of Thinking that Block Women's Paths to Power. San Francisco, CA: Jossey-Bass.

Garman, A. N., \& Lemak, C. H. (2011). Developing Healthcare Leaders: What We Have Learned, and What Is Next.

http://www.nchl.org/Documents/NavLink/NCHL_Developing_Healthcare_Leaders_Nov_2011_uid11212011137292.pdf.

Hassmiller, S., \& Combes, J. (2012). Nurse Leaders in the Boardroom: A Fitting Choice. Journal of Healthcare Management, 57, 8-11.

Hoss, M. A., Bobrowski, P., McDonagh, K. J., \& Paris, N. M. (2011). How Gender Disparities Drive Imbalances in Health Care Leadership. Journal of Healthcare Leadership, 3, 59-68. http://dx.doi.org/10.2147/JHL.S16315

Lantz, P. M. (2008). Gender and Leadership in Healthcare Administration: 21st Century Progress and Challenges. Journal of Healthcare Management, 53, 291-301.

Matus, J. C. (2003). The Movement for Diversity in Health Care Management. The Health Care Manager, 22, 117-121. http://dx.doi.org/10.1097/00126450-200304000-00006

McAlearney, A. S. (2008). Executive Leadership Development in US Health Systems: Exploring the Evidence. http://www.ache.org/pubs/research/McAlearney HMRA Report.pdf

McEldowney, R. P., Bobrowski, P., \& Gramberg, A. (2009). Factors Affecting the Next Generation of Women Leaders: Mapping the Challenges, Antecedents, and Consequences of Effective Leadership. Journal of Leadership Studies, 3, 24-30. http://dx.doi.org/10.1002/jls.20105

McKinsey \& Company (2010a). Moving Women to the Top. http://McKinseyquarterly.com/Moving_women_to_the_top_McKinsey_Global_Survey_results_2686

McKinsey \& Company (2010b). The Value of Centered Leadership. http://www.mckinsey.com/insights/leading_in_the_21st_century/the_value_of_centered_leadership_mckinsey_global_sur vey_results 
McKinsey \& Company (2010c). Women at the Top of Corporations: Making It Happen. http://www.asx.com.au/documents/media/2010_mckinsey_co_women_matter.pdf

McKinsey \& Company (2012). Making the Breakthrough. http://www.mckinsey.com/Features/Women Matter

Myers, V. L., \& Dreachslin, J. L. (2007). Recruitment and Retention of a Diverse Workforce: Challenges and Opportunities. Journal of Healthcare Management, 52, 290-298.

National Center for Healthcare Leadership (2010). Best Practices in Health Leadership Talent Management and Succession Planning: Case Studies. http://nchl.org/Documents/Ctrl_Hyperlink/doccopy5800_uid532012321522.pdf

Porter-O’Grady, T. (2003). A Different Age for Leadership, Part 2: New Rules, New Roles. Journal of Nursing Administration, 33, 173-178. http://dx.doi.org/10.1097/00005110-200303000-00009

Rosener, J. B. (1990). Ways Women Lead. Harvard Business Review, 68, 119-125.

US Bureau of Labor Statistics (2010). Occupational Employment Statistics: Overview. http://www.bls.gov/oes/oes emp.htm. Valian, V. (1998). Why So Slow? The Advancement of Women. Cambridge, MA: The MIT Press.

Warner, J. (2011). Diversity: Acting on What We Know. NACD Directorship. http://www.directorship.com/acting-on-what-we-know/

World Health Organization (2008). Gender and Health Workforce Statistics. http://www.who.int/hrh/statistics/spotlight2/en

Zenger, J., \& Folkman, J. (2012). Are Women Better Leaders than Men? Harvard Business Review. http://blogs.hbr.org/cs/2012/03/a_study_in_leadership_women_do.html 